\title{
LEGITIMIDADE CONSTITUCIONAL E DEMOCRÁTICA NOS NOVOS CONTEXTOS DO CONSTITUCIONALISMO
}

\author{
CONSTITUTIONAL AND DEMOCRATIC LEGITIMACY IN \\ THE NEW CONSTEXTS OF CONSTITUTIONALISM
}

Bruno Dias Magalhães

Mestre em Democracia y Buen Gobierno pela Universidade de Salamanca

Recebimento: 26/08/2017

Aprovação: 26/04/2018

\section{Como citar este artigo:}

Legitimidade constitucional e democrática nos novos contextos do constitucionalismo. MAGALHÃES, Bruno Dias. In: Revice - Revista de Ciências do Estado, Belo Horizonte, v.3, n.2, p. 331-330, jun./dez.2018. ISSN $2525-8036$.

RESUMO: O presente artigo busca analisar as influências e tensões existentes entre o constitucionalismo e a democracia, mais especificamente no que diz respeito a como os direitos, regras e princípios constitucionais potencializam ou socavam a deliberação política no atual contexto de pluralismo social. Além disso, busca-se analisar como a própria Constituição também é influenciada pela deliberação na esfera pública. Para tanto, parte-se do conceito de força normativa como pretensão de vigência, tal como formulado por Hesse (1992), trazendo-o à luz das perspectivas doutrinárias mais recentes, em consonância com os novos contextos do constitucionalismo. O exercício realizado permite reconhecer ao menos três aspectos inerentes à relação entre constitucionalismo e democracia. Primeiramente, em um contexto de pluralismo, os conflitos sociais não podem ser esgotados apenas no plano do texto fundamental, requerendo atuação da política infraconstitucional. Em segundo lugar, cada participante atua na realização da norma constitucional de maneira parcial, contingente e mais ou menos mediada, sendo que as posições são determinadas pelas regras democráticas vigentes. Finalmente, a legitimidade democrática é capaz de produzir influências na legitimidade constitucional e vice-versa. Como proposta de estudos futuros, sugere-se a aplicação do arcabouço teórico formulado a análises empíricas.

PALAVRAS-CHAVE: constitucionalismo; democracia; deliberação; força normativa

331 MAGALHÃES, Bruno Dias. Legitimidade constitucional e democrática nos novos contextos do constitucionalismo. 


\begin{abstract}
The present article seeks to analyze the influences and tensions between constitutionalism and democracy, specifically with respect to how constitutional rights, rules and principles potentiate or undermine political deliberation in the current context of social pluralism. In addition, it seeks to analyze how the Constitution itself is also influenced by deliberation in the public sphere. In order to do so, it starts from the concept of normative force as a pretension of validity, as formulated by Hesse (1992), bringing it in the light of the most recent doctrinal perspectives, in consonance with the new contexts of the constitutionalism. This exercise allows us to recognize at least three aspects inherent in the relationship between constitutionalism and democracy. Firstly, in a context of pluralism, social conflicts can not be exhausted only at the level of the fundamental text, requiring action by the infraconstitutional policy. Second, each participant acts in the accomplishment of the constitutional norm in a partial, contingent and more or less mediated way, and the positions are determined by the democratic rules in force. Finally, democratic legitimacy is capable of influencing constitutional legitimacy and vice versa. As a proposal for future studies, it is suggested to apply the theoretical framework formulated to empirical analysis.
\end{abstract}

KEYWORDS: constitutionalism; democracy; deliberation; normative force

\title{
INTRODUÇÃO
}

Nas sociedades contemporâneas, é inevitável considerar que o sistema político se conforma pela combinação, a um só tempo, de democracia e constitucionalismo. Tal combinação traz consigo diversas tensões, que por sua vez reclamam um afinado equilíbrio entre ambos os âmbitos. Isso ocorre porque a Constituição, como pacto fundacional de uma sociedade, estabelece um compromisso duplo. Por um lado, o compromisso dogmático com um rol de direitos e deveres, por outro, o compromisso orgânico com uma maneira específica de organização e distribuição de poder (NINO, 2006; BARAHONA, 2016).

Entretanto, como nos adverte Nino (2006), a falta de contornos precisos em relação à teoria democrática e ao constitucionalismo amiúde prejudica a identificação das tensões surgidas entre ambos, obscurecendo ou escamoteando a busca por suas soluções. O resultado pode converter a democracia em um método muito robusto para decidir sobre poucos temas - em alusão à predominância do constitucionalismo - ou um método excessivamente frágil para decidir 
questões demais - em alusão à predominância da democracia (NINO, 2006). O presente artigo busca contribuir com este debate a partir da análise sobre como os direitos, regras e princípios constitucionais potencializam ou socavam a deliberação política no atual contexto de pluralismo social. Além disso, busca-se analisar como a própria Constituição também é influenciada pela deliberação na esfera pública.

Para cumprir os objetivos propostos, partiremos de três premissas que, implícita ou explicitamente, assumem a compatibilidade entre o constitucionalismo e democracia. São elas: (i) que a gênese dos direitos fundamentais observa um processo circular permanente, no qual os direitos legítimos e o mecanismo pelo qual tais direitos são construídos (democracia) se constituem co-originariamente (HABERMAS apud CANOTILHO, 2002, p. 1386); (ii) que a auto vinculação estabelecida pela Constituição é democraticamente legítima não só porque advém de momentos constituintes de grande mobilização popular (ACKERMAN, 1989; ACKERMAN e ROSENKRANTZ, 1991), mas também porque o cumprimento de determinadas regras estabelecidas a priori tem o condão de potencializar o processo de aprendizado futuro das maiorias (HOLMES, 1993); e (iii) que a teoria deliberativa da democracia transcende o debate entre a política majoritária e as limitações impostas pelas garantias e liberdades civis, uma vez que se entende que as últimas nunca deixam de compor a agenda do debate público, embora necessitem de algumas condições especiais que vão além de acordos majoritários simples para que sejam transformadas (BENHABIB, 1996).

Dito isso, podemos seguir os passos de Gisbert (2005) no que diz respeito a sua compreensão da Constituição como um "sistema aberto de regras e princípios" que resulta de um "processo democrático deliberativo" e que, portanto, deve guardar clara conexão com a legitimidade democrática (p. 36). No entanto, à diferença do autor, não circunscreveremos nosso enfoque metodológico ao mero reconhecimento das distintas dimensões, para além do aspecto jurídico, da Constituição compreendida como cultura (HÄBERLE, 2000). Ao contrário, para alcançar os objetivos pretendidos, nosso foco será a conexão estabelecida entre o aspecto jurídico e o aspecto político da Constituição, entendida como uma expressão da herança cultural e das expectativas de um povo, em uma determinada etapa de desenvolvimento. Buscaremos tal conexão na ideia de força normativa tal como formulada por Hesse (1992), razão pela qual nosso objeto de estudo se desloca desde a noção estritamente jurídica de Constituição, para abarcar também a concepção mais alargada de política constitucional (ZAGREBELSKY, 2007).

333 MAGALHÃES, Bruno Dias. Legitimidade constitucional e democrática nos novos contextos do constitucionalismo. 


\section{Os cometidos da Constituição nos novos contextos do constitucionalismo: a força normativa como pretensão de vigência}

O Estado, como nos ensina Böckenförde (2000), somente pode atuar através da legitimidade democrática, que se estende desde o princípio de soberania popular até as competências dos órgãos estatais em uma cadeia ininterrupta (p.55). Desde esta perspectiva, a atuação estatal emerge de um ponto de partida funcional, orgânico e material, que deve ser originariamente legítimo, ou o que é equivalente, cuja legitimidade democrática está pressuposta, definida a priori.

Entretanto, argumenta Hesse (1992) que nem o Estado, nem mesmo o poder estatal, podem ser considerados como algo concluso, dado, adquirido. Ao contrário, na pluralidade de interesses, formas de atuação, valores e aspirações existentes na vida humana, o agir estatal somente adquire efetividade quando alcança certa unidade de ação social. Tal unidade, para o autor, não significa uma harmonia ou coincidência de interesses, tampouco supõe qualquer substância axiológica consensual, mas se relaciona com o consentimento tácito, isto é, a aceitação e o respeito por parte dos cidadãos a umas quantas normas e procedimentos, incluída a coerção estatal realizada para viabilizar determinados resultados. Em uma palavra, trata-se de uma unidade funcional, que deve ser assumida não somente pelos cidadãos perante o Estado, mas também nas relações de competição, disputa e cooperação inerentes à própria sociedade, as quais devem cingir-se à organização e aos procedimentos de uma determinada ordem jurídica (HESSE, 1992).

Na concepção do autor, portanto, a Constituição não emana de um Estado preexistente, independente da ação humana (p. 15), mas sim da formulação deontológica que busca alcançar duas tarefas principais, a saber: a unidade política e a ordem jurídica:

"La Constitución es el orden jurídico fundamental de la Comunidad. La Constitución fija los principios rectores con arreglo a los cuales se debe formar la unidad política y se deben asumir las tareas del Estado. Contiene los procedimientos para resolver los conflictos en el interior de la Comunidad. Regula la organización y el procedimiento de formación de la unidad política y la actuación estatal. Crea las bases y determina los principios del orden jurídico en su conjunto. En todo ello es la Constitución 'el plan estructural básico, orientado a determinados principios de sentido para la conformación jurídica de una Comunidad"” (HESSE, 1992, 16. Ênfase no original). 
Para Hesse (1992) a Constituição não é somente um ponto de partida, mas também um ponto de chegada, cujo alcance não pode ser produzido pelo mero efeito do texto fundamental e, por conseguinte, guarda relação com a ação humana, com a ação estatal e com as forças políticas, as quais a Constituição a um só tempo regula e deixa livres. Tal formulação assume a historicidade do Direito Constitucional, produzido "na diversidade das situações vitais" (p. 23), motivo pelo qual o cumprimento dos deveres da Constituição depende de um adequado equilíbrio entre sua abertura e amplitude, de um lado, e a virtude estabilizadora de suas disposições vinculantes, de outro. Em outras palavras, a Constituição deve cumprir o duplo papel de gerar estabilidade no que diz respeito ao estabelecimento de uma unidade política e de uma ordem jurídica, ao mesmo tempo em que se mantém aberta às sucessivas mudanças históricas (HESSE, 1992).

O conceito elaborado por Hesse (1992) se desenvolve em três aspectos fundamentais, os quais, a nosso ver, estão em permanente tensão nas atuais características das democracias pluralistas, que por sua vez, conformam os chamados novos contextos do constitucionalismo. São eles: (i) a Constituição gera legalidade, mas não necessariamente legitimidade, apesar de ambos elementos possuírem uma íntima conexão; (ii) a Constituição como norma requer realização, ou seja, vigência real, que, em que pese não ser absolutamente dependente da configuração social e política do presente, tampouco é totalmente independente dela; e (iii) o necessário equilíbrio entre abertura e vinculação do texto constitucional conduz à intrínseca conexão entre as questões de revisão e de mutação constitucional. Analisaremos cada aspecto segundo a formulação inicial de Hesse (1992), para então confrontá-los com os aludidos novos contextos.

A primeira questão se expressa na medida em que Hesse (1992) rejeita a legitimidade de qualquer acordo básico acerca dos conteúdos da ordem jurídica. Em outras palavras, não se reconhece como legítima a criação e a manutenção de "uma ordem pela ordem" (p.15). Ao contrário, na visão do autor a ordem deve vincular-se a uma substância justa e, por conseguinte, legítima. Os critérios de justiça viriam das experiências históricas convertidas em princípios jurídicos, que como mínimo deveriam ser capazes de estampar aquilo que não se demonstrou legítimo com o passar do tempo (HESSE, 1992).

Sem embargo, a perspectiva de legitimidade elaborada pelo autor não se esgota na vinculação do conteúdo da ordem jurídica a um rol de princípios de direito capazes de traduzir as experiências históricas. Para além disso, a legitimidade se expressa também na medida em que tal conteúdo converte-se em um acordo social respeitado por todos. Agora, tal acordo não é puramente estático, de tal maneira que pode ser deduzido regressivamente desde as competências

335 MAGALHÃES, Bruno Dias. Legitimidade constitucional e democrática nos novos contextos do constitucionalismo. 
constituídas até que se chegue a uma fonte última de poder, como havia proposto Böckenförde (2000). Se bem toda legitimidade advém da soberania popular, para Hesse (1992) essa soberania se expressa dinâmica, difusa e continuamente, através da manutenção e atualização permanente do acordo social.

Tal manutenção e atualização resultam de como se dá o processo de realização da Constituição, que para o autor ocorre quando esta adquire vigência real, isto é, seu conteúdo se transforma efetivamente em ação humana. O grau de vigência real de uma Constituição, anteriormente mencionado como o segundo aspecto fundamental da visão Hesse (1992), resulta de sua força normativa, que por sua vez depende tanto da possibilidade histórico contextual de realização de seu conteúdo, quanto da vontade de todos da comunidade em assumir a Constituição e agir em consonância com o plano estrutural por ela estabelecido. Nesse sentido, a força normativa é um elemento que emana do texto constitucional, não como força puramente imperativa da norma, mas sim como sua pretensão de vigência real. Nas palavras do autor:

"La norma constitucional puede ser operante cuando trata de construir de cara al futuro las circunstancias radicadas en la estructura individual del presente (...) Pero la fuerza normativa de la Constitución no se basa solamente en la adaptación inteligente a las circunstancias. La constitución jurídica misma es capaz de convertirse en fuerza actuante cuando se sitúa en la disposición individual del presente. Verdad es que por si sola no realiza nada sino que únicamente plantea una tarea. Pero se vuelve fuerza actuante cuando dicha tarea es asumida, cuando se está dispuesto a hacer determinar la conducta propia por el orden regulado por la Constitución, cuando se está decidido a imponer ese orden frecuente a cualquier cuestionamiento o ataque en base a circunstancias considerables de utilidad, cuando, por lo tanto, en la conciencia general y concretamente en la conciencia de los responsables de la vida constitucional se halla viva no solamente la voluntad de poder sino, sobre todo, la 'voluntad de Constitución”” (HESSE, 1992, 65-66).

O processo de realização da Constituição, por tanto, pressupõe sua força normativa, sem a qual, como bem recorda Lassalle (apud HESSE, 1992), o texto fundamental não passará de uma folha de papel. Operativamente, a realização da Constituição ocorre em todos os momentos de concretização da norma em situações reais. Tal concretização implica a incorporação das singularidades sociais concretas, que emanam da situação que se pretende regular, ao conteúdo normativo do preceito vinculante vigente. Ao fazê-lo, portanto, o processo de concretização da norma acaba por gerar uma realidade "normatizada", chamada por Hesse (1992) de realidade constitucional. Essa realidade, por sua vez, transforma o sentido concreto da norma sem modificar seu texto, dando contornos ao que o autor denomina de mutação constitucional. 
Vale notar, no entanto, que em seus escritos Hesse (1992) expressamente inadmite a possibilidade de existência de uma realidade constitucional que seja contra a Constituição. Em outras palavras, é inconcebível uma realidade "normatizada" que seja manifestamente inconstitucional. Isso não quer dizer que na comunidade não exista nenhuma realidade que seja contraditória aos preceitos ditados pela Constituição. Ao contrário, significa que tal realidade deve ser convertida em uma situação constitucional, isto é, que se deve atuar sobre ela, que se deve leva-la em consideração para que, de alguma maneira, possa novamente vir a estar de acordo com a Constituição. Tal formulação leva Hesse (1992) a advertir que, assim como a normatividade constitucional, adquire relevância equivalente a política constitucional, cujo papel é gerar as condições para que se mantenha o acordo das realidades com a Constituição, ou melhor dizendo, os “pressupostos de uma realização legítima da Constituição” (p. 29).

Dessa forma, a legitimidade da Constituição nos escritos de Hesse (1992) já não mais se resolve exclusivamente a priori, senão se estende à capacidade, em termos de condições ou pressupostos, de realização da Constituição. Em outras palavras, já não se trata meramente de garantir a adequação da realidade a uma norma, emanada como ponto de partida fundamental, mas sim de garantir as condições necessárias para o alcance do resultado concreto dessa norma, que se relaciona com seu conteúdo normativo em chave de mútua configuração. Por essa razão, como vimos, a legitimidade da Constituição é algo dinâmico, relacionada à vontade dos múltiplos atores políticos, em constante disputa, competição e cooperação. De modo simplista, poderíamos aludir, a título de exemplificação, a uma situação na qual coexistam inúmeras realidades que já não mais assumem os preceitos constitucionais. Isso resulta em uma perda da legitimidade democrática da Constituição, o que não necessariamente afeta sua legalidade no curto prazo, mas que deve ser trabalhada pela política constitucional para que não leve a uma perda futura de ineficácia, ou até mesmo de substituição do texto constitucional.

Diante disso, e considerando que as realidades se transformam ao longo do tempo, decorre que a legitimidade tal como concebida por Hesse (1992) é eminentemente dotada de historicidade. Tal historicidade, inerente ao conceito de força normativa, remete à já aludida necessidade de equilíbrio constitucional entre abertura e vinculação. Nesse sentido, a mutação constitucional, que opera permanentemente no processo de concretização da norma, realiza uma verdadeira incorporação das singularidades histórico-sociais enquanto conteúdo normativo. Sem embargo, como vimos as possibilidades de mutação constitucional são limitadas na medida em que não pode haver contradição entre seu resultado e o conteúdo da Constituição. É dizer, a 
limitação à plasticidade da norma frente ao caso concreto tem que ser o próprio texto constitucional em seu conjunto.

Por essa razão, adverte o autor que "a problemática da revisão constitucional começa ali onde terminam as possibilidades de mutação constitucional” (p. 24). Uma Constituição que dá pouco espaço à mutação constitucional e dificulta reformas tende a descumprir seu "dever ser" frente à realidade histórica, já que não logrará incorporar as mudanças sociais em seu conteúdo normativo. Por outro lado, uma Constituição que pouco permite a mutação constitucional, mas que facilita os procedimentos de reforma tende a faltar com seu "dever ser" de função estabilizadora, já que toda atualização histórica deverá pautar-se por reformas constitucionais, um processo político sujeito a muitos interesses para além da mera pretensão atualizadora do texto constitucional. Por último, uma Constituição que permite amplas oportunidades de mutação constitucional pode estar frouxamente articulada e sistematizada, não chegando a definir com claridade suficiente os contornos da ordem jurídica fundamental da comunidade. Em todos os casos haverá uma debilidade da força normativa do texto constitucional (HESSE, 1992), de maneira que a pretensão de vigência da Constituição requer um delicado equilíbrio entre a abertura e a vinculação de seus dispositivos normativos. Essa questão encerra o terceiro aspecto fundamental da perspectiva hessiana.

Diante disso, o autor argumenta que a Constituição deve produzir duas condições principais de modo a potencializar sua força normativa. A primeira é a conformação material, isto é, de adequação do conteúdo da Constituição à já mencionada disposição individual do presente. Para Hesse (1992) isso significa evitar que o texto constitucional seja tomado por disposições puramente técnico-organizativas, ou atadas a interesses particulares ou conjunturais, ou ainda construídas sobre estruturas unilaterais. A norma constitucional deve limitar-se a estabelecer uns quantos princípios elementares, capazes de adaptar-se à mudança histórica das circunstâncias sociais, econômicas, políticas e espirituais, sem perder seu conteúdo essencial.

A segunda condição é a preservação da praxis constitucional, ou o que é equivalente, o respeito à Constituição como ato de vontade dos diferentes atores sociais. Isso requer, em linhas gerais, que não se utilize frequentemente da revisão constitucional sob pretextos de necessidades políticas. Além disso, é importante que os intérpretes constitucionais se restrinjam aos limites impostos pela realização do sentido da regulação normativa na situação regulada, ou em outras palavras, que a mutação constitucional esteja limitada pelo texto fundamental (1992). 


\section{Os novos contextos do Constitucionalismo e a legitimidade da Constituição}

Com independência da verificação concreta das condições mencionadas, a concepção hessiana de Constituição pode ser hoje considerada de aceitação geral, ao menos desde uma perspectiva eurocêntrica (DE LA VEGA, 2009). Sem embargo, o autor destaca algumas transformações recentes na teoria constitucional, que em sua concepção respondem aos novos contextos filosófico, teórico e político que, em seu conjunto, estão notadamente marcados pela amplificação do pluralismo. Tais transformações, a nosso modo de ver, vêm reforçar a limitação normativa da Constituição, que para cumprir seus cometidos, deve alcançar certo grau de ressonância com as demais forças políticas e sociais, tal como havia antecipado Hesse (1992). Nesse particular, a síntese acerca das posturas doutrinais contemporâneas realizada por De la Vega (2009) tem especial poder explicativo:

\footnotetext{
"Las características de posturas doctrinales tan matizadas y plurales sólo pueden sintetizarse aproximativamente. Parten en primer lugar de la conciencia de la crisis regulativa de la Constitución y de su pérdida relativa de centralidad y de carácter planificador. En segundo término, aceptan con Teubner que debe superarse la dicotomía política/derecho, reforzando la consideración del papel y autonomía de los sistemas sociales en su relación con los sistemas anteriores. En tercer lugar, conciben el binomio normatividad/normalidad helleriano en términos de un continuo proceso de ajuste y aprendizaje entre sistemas, donde la función prescriptiva de la Constitución se atenúa en aras de la necesaria adaptación sistemática. Por último, subrayan el papel del Derecho constitucional como 'discurso' no dominante pero sí posiblemente integrador de las distintas lógicas sociales. En definitiva, y a pesar del evidente peligro de debilitar la normatividad del texto constitucional, y de la dificultad de encontrar una plasmación concreta de unos postulados tan abstractos, vienen a llamar la atención sobre la existencia de unos límites a la eficacia y función de la norma, inherentes a su naturaleza y a su entorno" (DE LA VEGA, 2009, p. 185).
}

As mudanças doutrinais expostas podem ser classificadas no que a literatura vem chamando de Modelo Democrático Constitucional ou Estado Democrático Constitucional (HÄBERLE, 2000; CANOTILHO, 2002; ZAGREBELSKY, 2007). Este Estado se diferencia do Estado de Direito uma vez que não se estrutura somente sobre o pressuposto de uma liberdade negativa, que protege os direitos civis frente a atuação do poder público, mas está também alicerçado, fundamentalmente, sobre uma liberdade positiva apoiada no exercício democrático do poder. Em outras palavras, tal como formula Canotilho (2002), não se trata de assumir a precedência do homem civil ao homem político, mas sim de reconhecer a co-originalidade de 
ambos. Essa perspectiva reforça a ideia de dupla legitimidade da ordem constitucional formulada por Hesse (1992): uma legitimidade de direito, consonante aos princípios de direito e aos direitos fundamentais, e uma legitimidade resultante do permanente acordo em torno do conteúdo da Constituição, condicionada ao alcance de seu "dever ser". A segunda, enfatize-se, trata-se de uma legitimidade de ordem democrática, política, e que agora pode ser plenamente assumida em sua condição de complementariedade à legitimidade jurídica.

No Estado Democrático Constitucional, portanto, o pluralismo intrínseco aos novos contextos é incorporado pela própria Constituição. Dessa maneira, a realização da Constituição cada vez mais requer a construção democrática das soluções no mundo real. $\mathrm{O}$ empoderamento como reconhecimento das distintas autonomias plurais traz em si uma visão político-jurídica que transcende a relação de exclusão e imposição do Estado de Direito, para abarcar a integração inclusiva "através da rede de valores e procedimentos comunicativos" da comunidade (ZAGREBELSKY, 2007, 15). Não se trata de abandonar a força normativa ao sabor das mudanças conjunturais da política, senão de reconhecer, como já o fez Hesse (1992), as limitações inerentes às normas legais, que ainda quando implementadas por meio da força ou coercitivamente, somente são efetivas na medida em que tal coerção é capaz de minar a resistência dos afetados pela norma na vida real. Por isso, até mesmo autores de bases teóricas muito distintas das aqui adotadas, como Grimm (2005), reconhecem que algumas funções da Constituição são eminentemente extranormativas, como é especialmente o caso da função integradora, que para Hesse (1992) torna-se nada menos que o principal "dever ser" constitucional.

Também a dinâmica da mutação constitucional, operada sobretudo através da interpretação, adquire nos novos contextos do constitucionalismo um caráter amplamente plural. Häberle (2008) aponta que cada realização da Constituição, quer dizer, cada vez que qualquer cidadão, grupo de cidadãos ou autoridade política atua de maneira a atualizar a Constituição, ainda que não consciente ou intencionalmente, sua atuação se converte em interpretação antecipada do texto constitucional. Com isso, o autor enfatiza a influência do autoentendimento dos indivíduos e grupos, a um só tempo sujeito de direitos e destinatários das normas, para a conformação do conteúdo normativo dessas próprias normas. Mais além, segundo esta perspectiva, o papel do pluralismo constitucional não se dá somente no momento do surgimento da norma ou nos canais institucionalizados de interpretação constitucional, mas também no seu desenvolvimento diário, no que o autor chama de "law in public action" (p. 43), isto é, através da comunicação permanente entre Estado e sociedade. 
Parte dessa comunicação, afirma Häberle (2008), é assumida pelos participantes estatais da interpretação e parte ocorre por meio dos participantes não estatais, sejam eles demandantes judiciais que exigem a tomada de decisão por parte de juízes, sejam eles expertos, peritos, lobistas, grupos de advocacy, ou sejam ainda cidadãos comuns em suas tarefas e autocompreensão cotidianos. O grau de mediação entre o autoentendimento dos diversos participantes e a conformação última da norma é definido pelo que o autor denomina de processo político, que já "não está excluído da Constituição, senão que se torna um de seus mais fundamentais âmbitos vitais e funcionais (...)" (HÄBERLE, 2008, p. 39). As interações entre os distintos entendimentos e atualizações compõem a publicidade e realidade da norma, a partir da qual (e somente a partir desta) decide o intérprete último, o juiz constitucional.

Como se vê, os novos contextos não conduzem a uma rejeição das formulações de Hesse (1992) sobre a legitimidade, a realização e a mutação da Constituição, entendida como ordem fundamental de uma comunidade. Ao contrário, em vez disso promove uma ampliação dos postulados hessianos, por meio da qual o conceito de força normativa como pretensão de vigência, bem como seus limites, adquire ainda maior relevância. A Constituição é, hoje mais do que nunca, norma fundamental da comunidade, se, e somente se, lograr adquirir força normativa para cumprir seu "dever ser".

Assim, a teoria da Constituição se aproxima da teoria da Democracia, através da interconectividade, ou inclusive da superposição, entre o conceito de legitimidade adotado por ambas. Do ponto de vista do constitucionalismo aqui adotado, a legitimidade democrática da Constituição emerge da permanente manutenção do acordo fundamental e do alcance de seu "dever ser". O maior ou menor grau de legitimidade de uma Constituição faz com que esta detenha uma maior ou menor força normativa, dadas as condições materiais de sua realização e dada a praxis constitucional vigente. Por outro lado, desde o ponto de vista da teoria democrática, em particular da teoria deliberativa, a legitimidade democrática emerge de uma maior ou menor ressonância entre os distintos discursos, em permanente formação e oposição na esfera pública, e a atuação estatal. Tal ressonância varia de acordo com o grau de deliberação dos espaços relacionais existentes entre representantes e representados, conformando perifericamente a comunicação Estado-Sociedade, seja essa expressa por canais formais de democracia, como eleições, instituições participativas etc., seja por canais informais de contrademocracia, revelada pela desconfiança cidadã e exercida por meio da vigilância, soberania negativa, juízo político (DRYZEK, 2001; 2010; HENDRIKS, 2006; MANSBRIDGE, 1996, ROSANVALLON, 2006). 
A conexão entre ambos os conceitos de legitimidade democrática, ao que tudo indica, opera por meio da política constitucional, que se situa no limiar entre a normatividade e a realidade (ou normalidade em termos hellerianos) e que está, como vimos, em permanente processo de ajuste e aprendizagem. Uma boa definição de política constitucional é a formulada por Ackerman (1999), a saber, trata-se de um momento extraordinário, marcado por uma série de movimentos políticos de grande mobilização popular, capaz de gerar a autorização para manifestar-se em nome do povo (p. 462). O falar em nome do povo significa, em linhas gerais, renovar a vontade fundacional (GARGARELLA E COURTIS, 2009), restabelecer o pacto fundamental, estabelecer um novo paradigma, mudar as regras do jogo.

No entanto, a Constituição requer estabilidade, como advertiu Hesse (1992), ou nas palavras de Gargarella e Courtis, certo “ar de intangibilidade” (p. 17). Não por outra razão Ackerman (1999) denomina sua perspectiva de teoria dualista da democracia, uma vez que nela se distinguem claramente os momentos extraordinários da política constitucional - quando são tomadas decisões fundantes - dos momentos ordinários da política comum - quando se tomam decisões políticas restritas ao marco constitucional vigente. A mencionada dualidade entre os momentos constitucionais e os momentos ordinários é necessária não somente para garantir a estabilidade do sistema político, sob pena de que a banalização da Constituição debilite sua força normativa, mas também para dotar de relevância a política ordinária que, ao fím do dia, é a responsável por levar a cabo os acordos constitucionais (GARGARELLA E COURTIS, 2009). Nessa mesma linha, e finalmente, Negretto (2009) argumenta que as frequentes mudanças constitucionais podem levar à quebra de expectativas dos cidadãos, que passam a enxergar a Constituição como um documento estéril para a melhoria concreta da sociedade ou, até mesmo, um mero instrumento de poder utilizado pelo governo de turno. Ambos os casos conduzem a uma perda de autoridade do texto fundamental, que é um conceito análogo à debilidade da força normativa, nos termos aqui propostos.

A dualidade da democracia, conforme mencionado no início do presente trabalho, é, portanto, compatível com a teoria da democracia deliberativa. Tal perspectiva, concatenada com as ideias já mencionadas de Häberle (2008), assume que a deliberação, desde logo realizada no marco dos direitos e autovinculação constitucionalmente atribuídos, a todo momento gera novos sentidos constitucionais. A política constitucional, portanto, é a que estabelece os critérios através dos quais os distintos sentidos constitucionais presentes na contestação deliberativa de discursos podem elevar-se ao status de efetivo conteúdo normativo constitucional. Nas palavras de Zagrebelsky: 
"La asunción del pluralismo en una Constitución democrática es simplemente una propuesta de soluciones y coexistencias posibles, es decir, un 'compromiso de posibilidades' y no un proyecto rígidamente ordenado de arriba hacia abajo. Sólo así podremos tener constituciones 'abiertas', constituciones que permitan, dentro de los límites constitucionales, tanto la espontaneidad de la vida social como la competición para asumir la dirección política, condiciones ambas para la supervivencia de una sociedad pluralista y democrática. Será la política constitucional que derive de las adhesiones y de los abandonos del pluralismo, y no la Constitución, la que podrá determinar los resultados constitucionales concretos. Para darse cuenta de esta transformación, ya no se puede pensarse en la Constitución como centro del que todo derivaba por irradiación a través de la soberanía del Estado en que se apoyaba, sino como centro sobre el que todo debe converger; es decir, más bien como centro a alcanzar que como centro del que partir. La 'política constitucional' mediante la cual se persigue ese centro no es ejecución de la Constitución, sino realización de la misma en uno de los cambiantes equilibrios en los que puede hacerse efectiva" (ZAGERBELSKY, 2007, 14).

\section{CONSIDERAÇÕES FINAIS}

Se a construção realizada até o momento possui algum sentido, é imperativo reconhecer ao menos três aspectos inerentes à relação entre constitucionalismo e democracia.

Primeiramente, em uma sociedade plural, o conceito de unidade funcional de Hesse (1992), ou ainda a perspectiva do caráter extra normativo da função integradora da Constituição de Grimm (2005), pressupõe que os conflitos sociais não podem ser plenamente solucionados no âmbito do pacto fundamental. Assim, parte desse conflito é absorvido pela pluralidade do texto constitucional, o que desloca a função de solução para o momento de realização da norma, que ocorre eminentemente na esfera da política ordinária, seja pelos participantes estatais (Legislativo, Executivo ou Judiciário), seja pelos participantes não estatais (potencialmente toda a comunidade, mas essencialmente grupos organizados da sociedade civil). Eventualmente, a solução alcançada historicamente é plasmada como norma por meio de reformas constitucionais, ou pela interpretação em última instância do juiz constitucional. Se por acaso o conteúdo agregado é tal que se pode falar em uma transformação do pacto fundacional, ou uma mudança nas regras do jogo, estamos frente a um momento constitucional.

Em segundo lugar, cada participante atua na realização da norma constitucional de maneira parcial, contingente e mais ou menos mediada. A forma de institucionalização

343 MAGALHÃES, Bruno Dias. Legitimidade constitucional e democrática nos novos contextos do constitucionalismo. 
democrática histórico-social irá determinar as potencialidades e limitações de cada participante no jogo democrático, dado o marco de possibilidades demarcado pela atribuição de direitos, divisão de poderes, configuração organizativa e pelas autovinculações constitucionais. Além disso, como vimos, a institucionalização democrática, ao conformar perifericamente o aparato estatal, gera incentivos para que a esfera pública adquira distintas formas de organização, formação e expressão da vontade e opinião política. Ainda assim, a participação de cada participante está circunscrita aos limites da mutação constitucional, a saber, ao texto da Constituição. Uma das consequências desse permanente diálogo entre atuação política e Constituição pode ser o crescente fenômeno da judicialização da política (AVRITZER E MARONA, 2014; BARAHONA, 2016), que por sua vez engloba a "juridificação" dos comportamentos políticos, entendidos como tradução das demandas políticas em termos jurídicos (NOBRE, 2008).

Finalmente, a legitimidade democrática da atuação estatal que, como postulamos, está em constante disputa na medida em que depende da ressonância de tal atuação com a deliberação pública, pode ou não gerar efeitos na legitimidade democrática da Constituição, e vice-versa. Por exemplo, uma extrema polarização da esfera pública, resultante de uma baixa ressonância desta com o governo, pode minar as bases do pacto fundamental que sustém a autovinculação constitucional, pressionando por frequentes mudanças nas regras do jogo. Por outro lado, um desenho constitucional inadequado com respeito às divisões do poder pode levar à dificuldade de institucionalização democrática, concentrando demasiadas prerrogativas em um determinado poder, de tal modo que ele se converta em uma espécie primus inter pares e impeça o apropriado desenvolvimento dos demais. Por último, a superposição de ambas legitimidades, levada a extremos tais que eliminem a dualidade entre a política constitucional e a política ordinária, pode gerar casos de constitucionalização da política comum ou, ao contrário, de banalização da Constituição, como apontam Gargarella e Courtis (2009).

As formulações aqui realizadas estão em consonância com a perspectiva de Sustein (1999), para quem o objetivo central da democracia constitucional é assegurar um âmbito de adequada deliberação pública, de maneira que o choque entre democracia e constitucionalismo não é algo inevitável. $\mathrm{O}$ autor sugere que a resposta a esta tensão dificilmente pode ser encontrada em uma análise abstrata. Parece-lhe mais produtivo "buscar concepções apropriadas de democracia e disposições constitucionais que as apoiem em lugar de debilita-las” (p. 368). Diante disso, aponta-se a análise das influências entre o sistema político e as caraterísticas constitucionais como importante agenda de pesquisa, de modo inspirar futuros estudos empíricos. 


\section{REFERÊNCIAS BIBLIOGRÁFICAS}

ACKERMAN, Bruce (1989). Constitucional Politics / Constitucional Law. The Yale Law Journal, Vol. 99, No. 3.

ACKERMAN, Bruce e Carlos F. Rosenkrantz (1991). Tres Concepciones de la Democracia Constitucional. In: CENTRO DE ESTUDIOS POLÍTICOS Y CONSTITUCIONALES. Fundamentos y Alcances del Control Judicial de Constitucionalidad. Colección Cuadernos y Debates, N. 29. Madrid.

AVRITZER, Leonardo e Marjorie Corrêa Marona (2014). Judicialização da Política no Brasil: ver além do constitucionalismo liberal para ver melhor. Revista Brasileira de Ciência Política, n. 15 , pp. 69-94.

BARAHONA, Elena Martínez (2016). El Poder Judicial en un Sistema Político Democrático. In: BARREDA, Mikel e Leticia M. Ruiz Rodriguez [coord.] Análisis de la política: enfoques y herramientas de la ciencia política. Huygens Editorial.

BENHABIB, Seyla (1996). Toward a Deliberative Model of Democratic Legitimacy. In: BENHABIB, Seyla (Ed.). Democracy and Difference. New Jersey: Princeton University Press.

BÖCKENFÖRDE, Ernst Wolfgang (2000). Estudios sobre el Estado de Derecho y la Democracia. Madrid: Editorial Trotta.

CANOTILHO, José Joaquim Gomes (2002). Direito Constitucional e Teoria da Constituição.

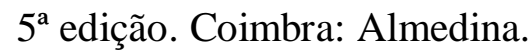

DE LA VEGA, Augusto Martín (2009). En Torno a la Teoría de la Constitución y los Nuevos Contextos del Constitucionalismo. Estudios de Deusto, Vol. 57/2, Bilbao, pp. 167-191.

DRYZEK, John S (2010). Foundations and Frontiers of Deliberative Governance. Oxford: Oxford University Press.

DRYZEK, John S. (2001). Legitimacy and Economy in Deliberative Democracy. Political Theory, Vol. 29, No. 5, pp. 651-669. 
GARGARELlA, Roberto e Christian Courtis (2009). El Nuevo Constitucionalismo Latinoamericano: promesas e interrogantes. Santiago de Chile: CEPAL, Serie Políticas Sociales.

GISBERT, Rafael Bustos (2005). La Constitución Red: un estudio sobre supraestatalidad y constitución. IVAP.

GRIMM, Dieter (2005). Integration by Constitucion. I-CON, Vol. 3, Nos 2-3: especial issue may, pp. 193-208.

HÄBERLE, Peter (2000). The Constitutional State and Its Reform Requirements. Ratio Juris, Vol. 13, No. 1, pp. 77-94.

HÄBERLE, Peter (2008). La Sociedad Abierta de los Intérpretes Constitucionales: una contribución para la interpretación pluralista y "procesal” de la Constitución. Academia. Revista sobre Enseñanza del Derecho. Ano 6, No. 11, pp. 29-61.

HENDRIKS, Carolyn M. (2006). Integrated Deliberation: Reconciling Civil Society's Dual Role in Deliberative Democracy. Political Studies, Vol. 54, pp. 486-508.

HESSE, Konrad (1992). Escritos de Derecho Constitucional. 2a edición. Madrid: Centro de Estudios Constitucionales.

HOLMES, Stephen (1993). Precommitment and the Paradox of Democracy. In: ELSTER, Jon e Rune Slagstad (Ed.). Constitucionalism and Democracy. Cambridge University Press.

MANSBRIDGE, Jane (1996). Using Power/Fighting Power. IN: BENHABIB, Seyla (Ed.). Democracy and Difference. New Jersey: Princeton University Press.

NEGRETTO, Gabriel (2009). Paradojas de la Reforma Constitucional en América Latina. Journal of Democracy en español, Vol. 1, No. 1, pp. 38-54.

NINO, Carlos Santiago (2006). La Constitución de la Democracia Deliberativa. Gedisa Editorial.

NOBRE, Marcos (2008). Indeterminação e Estabilidade. Os 20 Anos da Constituição Federal e as Tarefas da Pesquisa em Direito. CEBRAP, Novos Estudos, Vol. 82.

ROSANVAllon, Pierre (2006). Democracia y Desconfianza. Revista de Estudios Políticos. N. 134, pp. 219-237. 
SUSTEIN, Cass R (1999). Constituciones y Democracia: epílogo. In: ELSTER, Jon e Rune Slagstad (Ed.). Constitucionalismo y Democracia. Fondo de Cultura Económica, México DF, pp. 344-371.

ZAGREBELSKY, Gustavo (2007). El Derecho Dúctil. Ley, derechos, justicia. $7^{\text {a }}$ edição. Madrid: Editorial Trotta.

347 MAGALHÃES, Bruno Dias. Legitimidade constitucional e democrática nos novos contextos do constitucionalismo. 